\title{
Routine ANC can Save Thousands of Maternal Lives: A Study in Medical College Hospital
}

Tasnuva Akter ${ }^{1 *}$, Farhat Hossain ${ }^{2}$, Ismat Jahan ${ }^{3}$

${ }^{1}$ Assistant Professor, Bikrompur Bhuiyan Medical College, Bikrompur, Dhaka, Bangladesh

${ }^{2}$ Professor \& Head, Department of Gynae and Obstetrics, Sir Salimullah Medical College, Dhaka, Bangladesh

${ }^{3}$ Junior consultant, Department of Gynae and Obstetrics, Japan East West Medical College, Turag, Dhaka, Bangladesh

DOI: $10.36347 /$ sjams.2020.v08i09.043

| Received: 12.09 .2020 | Accepted: 26.09.2020 | Published: 30.09.2020

*Corresponding author: Tasnuva Akter

Abstract

Original Research Article

Introduction: Antenatal care (ANC) is a routinely checkup service provided to a women during her pregnancy. Mainly, it aims to ensure the health of both the mother and the fetus and to reduce maternal mortality rate. It is evidenced that, ANC is one of the four pillars of Safe Motherhood Initiative; moreover, circulation of it begins from $18^{\text {th }}$ century and was developed in the $19^{\text {th }}$ century. Providing necessary information and advices to maintain maternal health, safe childbirth, postnatal recovery to a pregnant women and her family is the target of ANC. Aim of the study: This study aims to observe that routine ANC (Antenatal Care) can save thousands of maternal lives. Material \& Methods: We carried out an observatory study in the department of Obstetrics and Gynaecology, SSMC \& Mitford Hospital, Dhaka, Bangladesh during the period from July 2015 to June 2017. Our aim was to observe the association of maternal mortality with routine ANC. A total number of 48 cases were enrolled in this study using purposive sampling technique. Data were collected in a pre-designed data collection sheet from the records of maternal death cases of Mitford Hospital after taking permission from the authority. Necessary data were collected from admission register, case files and death certificates using a structured questionnaire. Results: Out of 48 patients, the mean age was $25.42 \pm 3.89$ years. Most of the patients $(45.83 \%)$ belonged to lower middle class and only $6.25 \%$ were from upper class family. $33.33 \%$ patients had hypertension, $22.92 \%$ patients arrived in hospital with delay and both unsafe abortion and cardiac diseases were in $10.42 \%$ patients which were all statistically significant $(\mathrm{p}=<0.05)$. Among the 48 study patients $40.0 \%$ had caesarean section, $20.0 \%$ vaginal delivery and maternal deaths occurred as undelivered in $11.0 \%$. 46.0\% of deaths occurred within 24 hours of hospital admission and $42.0 \%$ patients died after 48 hours. Conclusion: ANC was observed only in $6.25 \%$ of the total cases which we conclude as the main factor of maternal mortality in this study. Severe anemia, cardiac diseases, unsafe abortion, delay in hospital arrival, delay in referral \& diagnosis were found as the main factors in routine checkup in antenatal care (ANC). So, routine ANC could help to reduce maternal mortality.

Keywords: Antenatal Care (ANC), Maternal Mortality.

Copyright @ 2020: This is an open-access article distributed under the terms of the Creative Commons Attribution license which permits unrestricted use, distribution, and reproduction in any medium for non-commercial use (NonCommercial, or CC-BY-NC) provided the original author and source are credited.

\section{INTRODUCTION}

Antenatal care (ANC) is a routinely checkup service provided to a women during her pregnancy. Mainly, it aims to ensure the health of both the mother and the fetus and to reduce maternal mortality rate. It is evidenced that, ANC is one of the four pillars of Safe Motherhood Initiative [1], moreover, circulation of it begins from $18^{\text {th }}$ century [2] and was developed in the $19^{\text {th }}$ century [3]. Providing necessary information and advices to maintain maternal health, safe childbirth, postnatal recovery to a pregnant women and her family is the target of ANC. It also helps to ensure the health of newborn by assisting pregnant mothers with the information about baby care, promotion of early, exclusive breastfeeding, and guidance with deciding on future pregnancy outcomes. Statistics suggest that, about one million neonatal deaths occurs on the day of birth and approximately two million newborn survives only a week [4-6]. On the other hand, one mother dies in every minute with maternal complication in the developing countries [7], and not less than half a million mothers die in every year worldwide [8]. In South Africa, there is a difference in the maternal mortality ratio (MMR) between patients receiving antenatal care in tertiary hospitals $(29.8$ per 100,000 live births) and patients not receiving antenatal care in those facilities (304.7 per 100,000 live births) or not receiving antenatal care at all (348.5 per 100,000 live births)[9]. ANC is observed to be fully effective if 
properly given and if the mother is prepared to deliver with the help of skilled health attendant. ${ }^{10}$ Maternal Mortality Ratio (MMR) of Bangladesh was comparatively high but in recent times it has been reduced from one hundred and ninety-four to one hundred and seventy-six per one lakh livebirths between 2010 and 2015 [11,12]. This reduction might happen due to the improvement of ANC services and proper exclusive consultancy to the pregnant women by the healthcare providers. However, there is visible number of maternal death causing every year and deprived of proper healthcare-seeking actions of women and their families are often recommended as the most important encounters that must be addressed to further reduce the MMR in Bangladesh [13]. Therefore, aim of this study to observe that contribution of routine ANC in reducing maternal mortality.

\section{Methodology and Materials}

We carried out an observatory study in the department of Obstetrics and Gynaecology, SSMC \& Mitford Hospital, Dhaka, Bangladesh during the period from July 2015 to June 2017. Our aim was to observe the importance of ANC in reducing maternal mortality. A total number of 48 cases were enrolled in this study using purposive sampling technique. Data were collected in a pre-designed data collection sheet from the records of maternal death cases of Mitford Hospital after taking permission from the authority. Necessary data were collected from admission register, case files and death certificates using a structured questionnaire. At every step of data collection, processing and analysis, the procedure was followed strictly. Accuracy of data collection was ensured. For that purpose, at first work manual was made. Then a sample size and suitable study place were selected. A standard case record form was designed for data collection. The association between maternal mortality and antenatal care was observed by Chi-squared test where $\mathrm{p}<0.05$ considered as significant.

\section{RESULTS}

Table I shows the age distribution of the study patients. Out of 48 patients, it was observed that majority $(64.58 \%)$ patients belonged to the age group 20-29 years and only $10.40 \%$ were between $15-19$ years. The mean age was $25.42 \pm 3.89$ years. Table II showing the different socio-economic status of the study patients where most of the patients $(45.83 \%)$ belonged to lower middle class and only $6.25 \%$ were from upper class family. Table III shows the antenatal check-up status of the studied patients where only $6.25 \%$ had regular check-up, $20.83 \%$ had irregular check-up and $72.91 \%$ had never attended any antenatal check-up during pregnancy. Table IV shows the contributing factors of maternal death identifying by routine ANC. It was observed that $33.33 \%$ patients had hypertension, $22.92 \%$ patients arrived in hospital with delay and both unsafe abortion and cardiac diseases were in $10.42 \%$ patients which were all statistically significant $(\mathrm{p}<0.05)$. Figure I pie chart shows percentage distribution of the study patients on various modes of termination of pregnancy. It was observed that among the 48 study patients $40.0 \%$ had caesarean section, $20.0 \%$ vaginal delivery and maternal deaths occurred as undelivered in $11.0 \%$. Figure II pie chart shows percentage distribution of the study patients based on duration between admission in hospital and death. It was observed that $46.0 \%$ of deaths occurred within 24 hours of hospital admission and $42.0 \%$ patients died after 48 hours.

Table-I: Distribution of the study patients by age. $(n=48)$

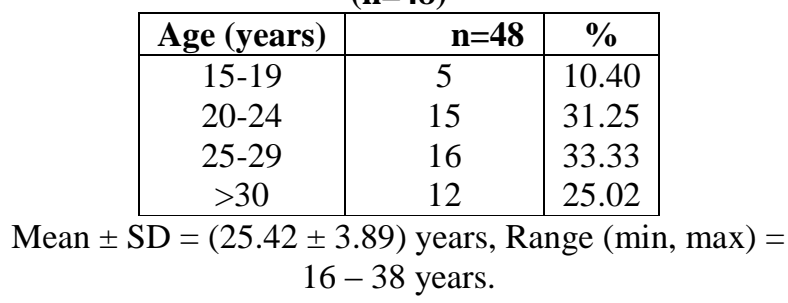

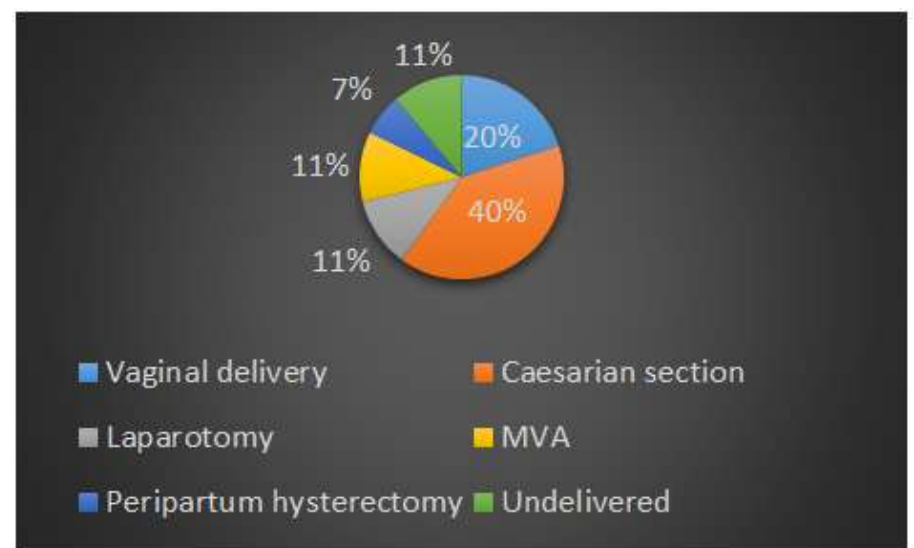

Fig-I: Distribution of various modes of termination of pregnancy $(n=48)$ 
Table-II: Distribution of socioeconomic status of participants $(n=48)$

\begin{tabular}{|l|c|c|}
\hline Socioeconomic status (taka/month) & n & \% \\
\hline Lower class (<10,000) & 15 & 31.25 \\
Lower middle class (10-20,000) & 22 & 45.83 \\
Upper middle class (21-30,000) & 8 & 16.67 \\
Upper class (> 30,000) & 3 & 6.25 \\
\hline
\end{tabular}

Table III: Antenatal check-up status of participants $(n=48)$

\begin{tabular}{|c|c|c|}
\hline Visits & n & \% \\
\hline Regular & 3 & 6.25 \\
\hline Irregular & 10 & 20.83 \\
\hline No check-up & 35 & 72.91 \\
\hline
\end{tabular}

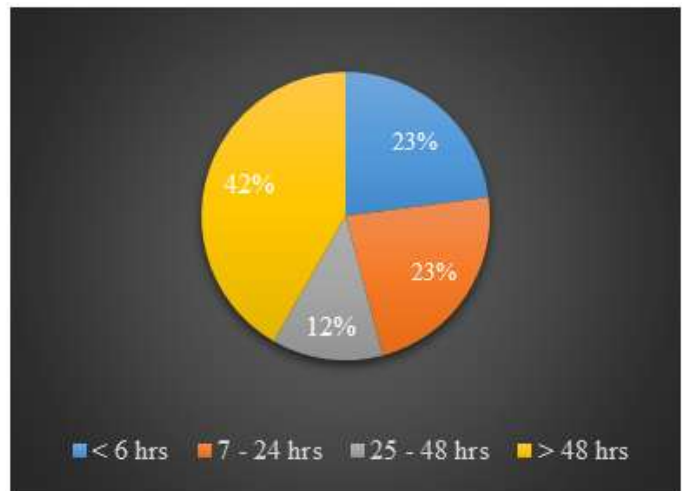

Fig-II: Duration between hospital admission and maternal death $(n=48)$

Table-IV: Distribution of the contributing factors of maternal death $(n=48)$

\begin{tabular}{|l|c|c|c|}
\hline Contributing factor & n & $\%$ & P-value \\
\hline Severe anemia & 9 & 18.75 & $\mathrm{P}<0.001$ \\
\hline Hypertension & 16 & 33.33 & $\mathrm{P}<0.001$ \\
\hline Cardiac diseases & 5 & 10.42 & $\mathrm{P}<0.001$ \\
\hline Unsafe abortion & 5 & 10.42 & $\mathrm{P}<0.001$ \\
\hline Delay in hospital arrival & 11 & 22.92 & $\mathrm{P}<0.001$ \\
\hline Delay in referral \& diagnosis & 2 & 4.17 & $\mathrm{P}<0.001$ \\
\hline Others & 3 & 6.25 & $\mathrm{P}<0.003$ \\
\hline
\end{tabular}

\section{DisCUSSION}

In this study most $(40 \%)$ of the patient had caesarian delivery, $20.0 \%$ had vaginal delivery and maternal deaths occurred as undelivered in $11.0 \%$. It is specified that, antenatal care offers opportunity to a women and her family during her pregnancy to be aware of the danger and probable complications to come [14]. Some study findings have also recognized the superiority of ANC as a contributing factor for the improved utilization of health facilities as a place for delivery [15-17]. Although, some evidence showed that most women who accessed ANC did not deliver in a healthy facility [18-22]. In our study, only $6.25 \%$ had regular check-up, $20.83 \%$ had irregular check-up and $72.91 \%$ had never attended any antenatal check-up during pregnancy. Absence of regular ANC and failure to give birth in health facility are the main obstacles for detecting the pregnancy related complications. Few studies done in Sub Saharan Africa have shown that less number of ANC visit was another leading reason behind maternal mortality [23-25]. Other studies have also revealed about 10-17 fold increased maternal death amongst women with no antenatal care [26, 27]. In coverage of at least 4 visits antenatal care, the least achiever country was Ethiopia in Sub Saharan Africa. The proportion of health facility delivery and antenatal care between 1995 and 2011 were in the range of 5\%$10 \%$ and $10 \%-19 \%$, respectively [28]. Therefore, the low proportion of antenatal care compounded by the extremely low skilled person attended delivery might be some of the major reasons for the high maternal mortality persisting during the last decade (873 and 676 per 100,000 live births in 2000 and 2011, respectively) $[28,29]$. Data based evidence are insufficient because there are a limited number of study done on the association of maternal mortality with ANC. Further study needs to be conducted to observe the association properly.

\section{Limitation OF THE STUdy}

It was an observational study with small sample size, which may not reflect the scenario of the whole country. To get more specific findings we would 
like to recommend for conducting similar more studies with larger sized sample.

\section{CONCLUSION}

Antenatal Care (ANC) was observed only in $6.25 \%$ of the total cases. Lack of ANC concludes as a major cause of maternal mortality. Inadequate ANC can interrupt the continuum of care, affecting both women and babies. We have observed $40 \%$ cases of Caesarian Section that indicates the critical condition of the studied patients. So, severely ill conditions were another main reason of maternal mortality in this study. The factors of severe anemia, cardiac diseases, unsafe abortion, delay in hospital arrival, delay in referral \& diagnosis were presented and were strongly associated with maternal mortality during antenatal care. So, routine ANC could help to reduce maternal mortality of this study.

\section{RECOMMENDATIONS}

Antenatal checkup is essential to reduce maternal death. Government along with NGOs and social workers should take necessary steps in this regards. Immediate attendance, evaluation and treatment on patient's arrival at the facility health center are recommended. Well coordination between the attending physician and the laboratory and blood bank staffs should be established. Maternal mortality surveillance system should be a routine practice in health care system. Gynecologists should also motivate patients to attend ANC regularly.

\section{REFERENCES}

1. World Health Organization. Mother-Baby package: Implementing safe motherhood in countries. Practical guide. WHO/FHE/MSM/94.11. World Health Organization; 1994.

2. Jacues G. History of Childbirth. Boston: Northern University Press. 1991; 96-98. Last accessed in November 2013.

3. Fiscella K. Does prenatal care improve birth outcomes? A critical review. Obstet Gynecol. 1995; 85(3):468-79.

4. You D, New J, Wardlaw T. Levels and trends in child mortality. Report 2015. Estimates developed by the UN Inter-agency Group for Child Mortality Estimation. 2015.

5. Dickson KE, Simen-Kapeu A, Kinney MV, Huicho L, Vesel L, Lackritz E. Every Newborn: healthsystems bottlenecks and strategies to accelerate scale-up in countries. The Lancet. 2014; 384 (9941):438-54.

6. UN. United Nations Millennium Declaration resolution 55/2. Fifty-fifth United Nations General Assembly, New York, 18 September; 2000. 2000.

7. World Health Organization. Maternal mortality in 2005: Estimates developed by WHO, UNICEF,
UNFPA and the World Bank. Geneva: WHO; 2007.

8. United Nations. The Millennium Development Goals report. 2005, New York, 2005.

9. Daponte A, Guidozzi F \&Marineanu A. Maternal mortality in tertiary center after introduction of free antenatal care. International Journal of Gynaecology and Obstetrics. 2000; 71: 127-133.

10. Hailu M, Gebremariam A, Alemseged F, Deribe K. Birth Preparedness and Complication Readiness among Pregnant Women in Southern Ethiopia. PLoS ONE 2011; 6(6): e21432.

11. National Institute of Population Research and Training (NIPORT), MEASURE Evaluation I, B. Bangladesh Maternal Mortality and Health Care Survey. 2010. Dhaka, Bangladesh; 2012.

12. WHO. Trends in maternal mortality: 1990 to 2015: estimates by WHO, UNICEF, UNFPA, World Bank Group and the United Nations Population Division. [cited 2016 Aug 27].

13. Koblinsky M, Anwar I, Mridha MK, Chowdhury ME, Botlero R. Reducing maternal mortality and improving maternal health: Bangladesh and MDG 5. J Health PopulNutr. 2008;26:280

14. Palaniappan B. Role of antenatal care in Safe Motherhood. J Indi Med Asso. 1995: 93:52-54

15. Tann CJ, Kizza M, Morison L. Use of antenatal services and delivery care in Entebbe, Uganda: a community survey. BMC Pregnancy Childbirth. 2007; 7:23.

16. Pervin J, Moran A, Rahman M. Association of antenatal care with facility delivery and perinatal survival - a populationbased study in Bangladesh. BMC Pregnancy Childbirth 2012; 12: 111.

17. Bloom SS, Lippeveld T, Wypij D. Does antenatal care make a difference to safe delivery? A study in urban Uttar Pradesh, India. Health Policy Plan. 1999; 14(1):38-48.

18. Tann CJ, Kizza M, Morison L. Use of antenatal services and delivery care in Entebbe, Uganda: a community survey. BMC Pregnancy Childbirth. 2007; 7:23.

19. Rockers PC, Wilson ML, Mbaruku G, Kruk ME. Source of antenatal care influences facility delivery in rural Tanzania: a population-based study. Matern Child Health J. 2009; 13(6):879-85.

20. Magoma M, Requejo J, Campbell OMR, Cousens S, Filippi V. High ANC coverage and low skilled attendance in a rural Tanzanian district: a case for implementing a birth plan intervention. BMC Pregnancy and Childbirth. 2010; 10:13.

21. Oguntunde O, Aina O, Ibrahim MS, Umar HS, Passano P. Antenatal Care and Skilled Birth Attendance in Three Communities in Kaduna State, Nigeria Afr J Reprod Health. 2010; 14(3): 89-96.

22. Pervin J, Moran A, Rahman M. Association of antenatal care with facility delivery and perinatal survival - a populationbased study in Bangladesh. BMC Pregnancy Childbirth. 2012; 12: 111. 
23. Publication search by country (DHS): http://www.measuredhs.com/pubs/

24. World health organization. World Health Statistics 2013. Last accessed in November. 2013: www.who.int/

25. Abebe F, Berhane Y, Girma B. Factors associated with home delivery in Bahirdar, Ethiopia: a case control study. BMC Res Notes. 2012; 5:653.

26. Garenne M, Mbaye K, Bah MD, Correa P. Risk factors for maternal mortality: a casecontrol study in Dakar hospitals (Senegal). Afr J Reprod Health. 1997; 1(1):14-24.
27. Igberase GO, Ebeigbe PN. Maternal mortality in a rural referral hospital in the Niger Delta, Nigeria. ObstetGynaecol. 2007; 27(3):275-8.

28. Central Statistical Agency [Ethiopia] and ICF International. 2012. Ethiopia Demographic and Health Survey 2011. Addis Ababa, Ethiopia and Calverton, Maryland, USA: Central Statistical Agency and ICF International.

29. Federal Democratic Republic of Ethiopia. Ministry of Health and Health Related Indicators. 2010/2011) 